\title{
High-temperature nanoindentation of epitaxial ZrB2 thin films
}

\author{
Esteban Broitman, Lina Tengdelius, Ude D. Hangen, Jun Lu, Lars Hultman and Hans \\ Högberg \\ Journal Article
}

\section{Tweet}

N.B.: When citing this work, cite the original article.

Original Publication:

Esteban Broitman, Lina Tengdelius, Ude D. Hangen, Jun Lu, Lars Hultman and Hans Högberg, High-temperature nanoindentation of epitaxial ZrB\&lt;sub\&gt;2\&lt;/sub\&gt; thin films, Scripta Materialia, 2016. 124(), pp.117-120.

http://dx.doi.org/10.1016/j.scriptamat.2016.06.033

Copyright: Elsevier

http://www.elsevier.com/

Postprint available at: Linköping University Electronic Press

http://urn.kb.se/resolve?urn=urn:nbn:se:liu:diva-130917

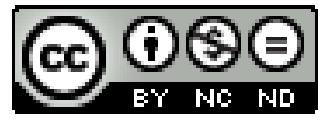




\title{
High-temperature Nanoindentation of Epitaxial ZrB 2 Thin Films
}

\author{
Esteban Broitman ${ }^{1}$, Lina Tengdelius ${ }^{1}$, Ude D. Hangen², Jun Lư ${ }^{1}$, Lars Hultman ${ }^{1}$, \\ Hans Högberg ${ }^{1}$
}

1. Thin Film Physics Division, Department of Physics, Chemistry, and Biology (IFM), Linköping University, SE-58183 Linköping, Sweden.

2. Hysitron Inc., Minneapolis, Minnesota 55344, USA.

\section{Abstract}

We use in-situ heated nanoindentation to investigate the high-temperature nanomechanical properties of epitaxial and textured $\mathrm{ZrB}_{2}$ films deposited by magnetron sputtering. Epitaxial films deposited on $4 \mathrm{H}$-SiC(0001) show a hardness decrease from $47 \mathrm{GPa}$ at room temperature to $33 \mathrm{GPa}$ at $600^{\circ} \mathrm{C}$, while the reduced elastic modulus does not change significantly. High resolution electron microscopy (HRTEM) with selected area electron diffraction of the indented area in a 0001-textured film reveals a retained continuous $\mathrm{ZrB}_{2}$ film and no sign of crystalline phase transformation, despite massive deformation of the Si substrate. HRTEM analysis supports the high elastic recovery of $96 \%$ in the films.

Keywords: sputtering; borides; ceramic thin film; nanoindentation; transmission electron microscopy

Zirconium diboride $\left(\mathrm{ZrB}_{2}\right)$ is a high-melting point ceramic that has been shown to exhibit high hardness and elastic modulus as well as good wear-corrosion resistance in the bulk form [1]. These properties are potentially useful for thin film applications, like cutting tools, aerospace, and electronics [2]. Thin film growth of $\mathrm{ZrB}_{2}$ with welldefined properties is, however, complicated as the literature reports nonstoichiometric films or films with high amount of contaminants, especially oxygen. A promising advancement is our recent demonstration of epitaxial growth of stoichiometric $\mathrm{ZrB}_{2}$ films by direct current magnetron sputtering (DCMS) using a $\mathrm{ZrB} 2$ compound target [3] [4].

Few data on high-temperature hardness and Young's modulus of $\mathrm{ZrB}_{2}$ have been published for bulk single-crystal and polycrystalline material. Nakano and Matsubara reported the Knoop hardness of single-crystal $\mathrm{ZrB}_{2}$ [5]. They found that the hardness in each plane of the crystal decreases monotonously in the temperature range 300- 
$1100{ }^{\circ} \mathrm{C}$ from 27 to $9.8 \mathrm{GPa}$ when the indentation is done on the $\{0001\}$ plane, and from 20 to $6 \mathrm{GPa}$ on the $\{1010\}$ plane. Xuan et al also studied the microhardness of single-crystals, but using a Vickers indenter with a load of $200 \mathrm{~g}$ [6]. The hardness is reported to decrease rapidly from $21.3 \mathrm{GPa}$ at room temperature to $12 \mathrm{GPa}$ at $400^{\circ} \mathrm{C}$, then the decrease slows down to $9 \mathrm{GPa}$ at $700^{\circ} \mathrm{C}$, and finally reaches a constant value of $7.85 \mathrm{GPa}$ at $1000^{\circ} \mathrm{C}$. Bsenko and Lundström studied the Vickers microhardness of polycrystals with an applied load of $50 \mathrm{~g}$ [7]. They reported a hardness decrease from $30 \mathrm{GPa}$ to $8.5 \mathrm{GPa}$ when the temperature is increased from 25 to $600{ }^{\circ} \mathrm{C}$. Wang et al developed a cross-bar Vickers technique for determining the hardness of polycrystalline hot-pressed $\mathrm{ZrB}_{2}$ at very high temperatures, up to $2000{ }^{\circ} \mathrm{C}$ [8]. Their experiments show that $\mathrm{H}$ decreases from $6.2 \mathrm{GPa}$ at $1100^{\circ} \mathrm{C}$ to $0.6 \mathrm{GPa}$ at $2000{ }^{\circ} \mathrm{C}$. Regarding Young's modulus, Okamoto et al found a monotonically decrease from 525 to $475 \mathrm{GPa}$ when the temperature increases from 25 to $1100^{\circ} \mathrm{C}$ on their polycrystalline material [9], while Wiley et al, measuring also polycrystalline $\mathrm{ZrB} 2$ samples, reported a decrease from 493 to $448 \mathrm{GPa}$ when the temperature increases from $25^{\circ} \mathrm{C}$ to 1000 ${ }^{\circ} \mathrm{C}$ [10]. To our knowledge, no data is available about the high-temperature hardness and elastic modulus of $\mathrm{ZrB}_{2}$ films.

In this work, we investigate the high temperature nanomechanical properties of epitaxial $\mathrm{ZrB}_{2}$ films deposited by DC magnetron sputtering from a 3-inch circular target on $4 \mathrm{H}-\mathrm{SiC}(0001)$, as well as weakly $10 \overline{1} 0$ textured $\mathrm{ZrB}_{2}$ films grown on $\mathrm{Si}(100)$ held at floating potential using a deposition process described recently [3]. The deposition temperature and power discharge were $900{ }^{\circ} \mathrm{C}$ and $425 \mathrm{~W}$ for the film on SiC, and 850 ${ }^{\circ} \mathrm{C}$ and $400 \mathrm{~W}$ for the film on $\mathrm{Si}$, respectively. For comparison, we investigated 0001 textured $\mathrm{ZrB}_{2}$ films deposited on $\mathrm{Si}(100)$ without external heating and at process conditions reported in [11], as well as bulk samples of polycrystalline $\mathrm{ZrB}_{2}$. All films were deposited to a thickness of $\sim 400 \mathrm{~nm}$.

X-ray diffraction (XRD) $\theta / 2 \theta$ scans were performed to determine the structural properties of the films, using a Philips PW1820 diffractometer equipped with a $\mathrm{Cu} \mathrm{Ka}$ source operated at $40 \mathrm{kV}$ and $40 \mathrm{~mA}$. Figure 1 shows $\theta / 2 \theta$ diffractograms obtained from $\mathrm{ZrB}_{2}$ films deposited at high temperature on $4 \mathrm{H}-\mathrm{SiC}(0001)$ and $\mathrm{Si}(100)$ substrates. The film deposited on $\mathrm{SiC}(0001)$ (Figure 1a) shows peaks of high intensities corresponding to the 0001, 0002, 0003, and 0004 peaks of the $\mathrm{ZrB}_{2}$ phase. Weaker $\mathrm{ZrB}_{2} 10 \overline{1} 1,10 \overline{1}$, and $10 \overline{1} 3$ peaks can also be observed. Other peaks visible 
are $000 \ell$ from the SiC substrate. The high intensities of the $\mathrm{ZrB}_{2} 000 \ell$ peaks indicate that the film is well-ordered [12]. Recently we have shown that the intensity of these extra peaks decreases when the deposition temperature increases from 500 to $900{ }^{\circ} \mathrm{C}$ [4].
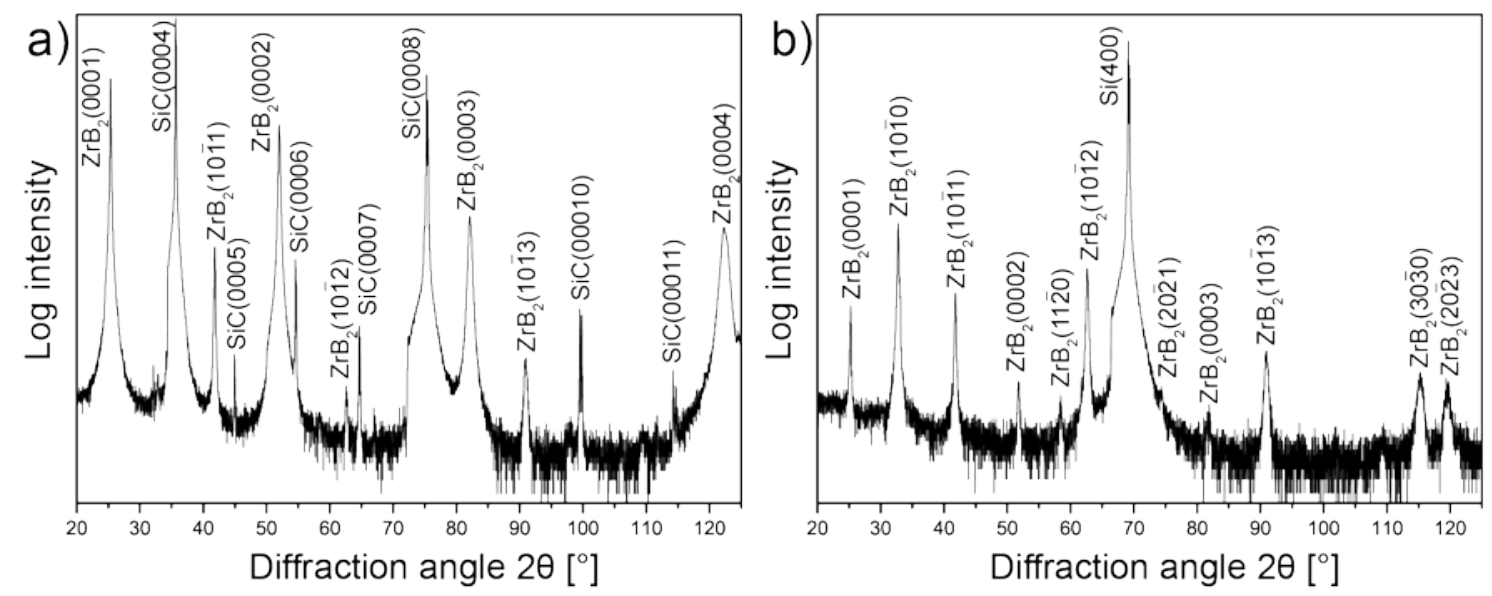

Figure 1: $\theta / 2 \theta$ XRD diffractograms of coatings deposited on (a) $4 H-S i C(0001)$ at $900{ }^{\circ} \mathrm{C}$, and (b) $\mathrm{Si}(100)$ at $850^{\circ} \mathrm{C}$.

The $\theta / 2 \theta$ diffractogram recorded from a film deposited on $\mathrm{Si}(100)$ (Figure $1 \mathrm{~b}$ ) displays a dominating $\mathrm{Si}(400)$ peak from the substrate and with the $10 \overline{1} 0$ peak being of highest intensity for $\mathrm{ZrB}_{2}$, as well as weaker $000 \ell, 10 \overline{1} \ell, 30 \overline{3} 0$ and $20 \overline{2} 3$ peaks. Fainting $11 \overline{2} 0$ and $20 \overline{2} 1$ peaks are also detected. The intensity distribution among the $\mathrm{ZrB}_{2}$ peaks shows that the film is weakly 1010 textured and where their low intensities compared to that of the Si 400 peak is characteristic of a lower crystal quality compared to that of the film grown on $\operatorname{SiC}(0001)$.

The hardness $(H)$ and reduced Young's modulus $\left(E_{r}\right)$ as well as the elastic recovery $\left(\mathrm{W}_{\mathrm{e}}\right)$ were investigated using a Hysitron Triboindenter TI950 instrument provided with a $\mathrm{XSol}^{\mathrm{TM}}$ high temperature heating stage operating in the range $25-600{ }^{\circ} \mathrm{C}$. The nanoindentations were conducted using a high-temperature Berkovich diamond probe (Hysitron). An inert gas environment $\left(\mathrm{N}_{2}\right.$ containing $\left.5 \% \mathrm{H}_{2}\right)$ was used at an oven-like, gas flooded volume around the sample to prevent oxide formation. The specimen was first heated to a selected temperature. A waiting period of 10-20 min was used to reach thermal equilibrium. The indentation tip was then engaged in contact with the film surface, and 20-30 indents were performed. Once the experiments were finished, the temperature was increased to the next selected value. In all the nanoindentation 
experiments the penetration depth of the indenter was kept lower than $10 \%$ of the film thickness to avoid influence from the substrate. $H$ and $E_{r}$ were calculated by the method of Oliver and Pharr using the unloading elastic part of the load-displacement curve [13]. The elastic recovery was calculated as $W_{e}=100 \times\left(h_{m}-h_{f}\right) / h_{m}$, where $h_{m}$ is the maximum penetration depth (produced at the maximum indentation load) and $h_{f}$ corresponds to the final displacement after complete unloading. Tip-shaoe controls done after the tests at room temperature, $400{ }^{\circ} \mathrm{C}$, and $600{ }^{\circ} \mathrm{C}$ have shown no change in the area function.

Table 1 gives $H, E_{r}$, and $W_{e}$ measured at room temperature for different films. For comparison, the values for a $\mathrm{ZrB}_{2}$ thin film deposited at room temperature, and a spark plasma sintered polycrystalline bulk sample obtained at $1900{ }^{\circ} \mathrm{C}$ [14] are also indicated. Thin film hardness decreases as the crystal quality of the films reduces but, interestingly, the elastic recovery measured at room temperature keeps at the same high value (96\%) in all films. On the other hand, the $\mathrm{ZrB}_{2}$ bulk sample has a $\mathrm{W}_{\mathrm{e}}=81 \%$.

Table 1: Comparison of hardness $H$, reduced elastic modulus $E_{r}$, and elastic recovery $W_{e}$ measured at room temperature.

\begin{tabular}{|l|c|c|c|}
\hline \multicolumn{1}{|c|}{$\mathbf{Z r B}_{\mathbf{2}}$} & H (GPa) & Er $_{\mathbf{r}}$ (GPa) & We (\%) \\
\hline Epitaxial/SiC, deposited at $900{ }^{\circ} \mathrm{C}$ & $47.3 \pm 0.2$ & $359 \pm 8$ & 96 \\
\hline Weakly textured/Si, deposited at $850{ }^{\circ} \mathrm{C}$ & $30.8 \pm 0.2$ & $243 \pm 8$ & 96 \\
\hline 0001 Textured/Si, deposited at $\sim 25^{\circ} \mathrm{C}$ & $24.6 \pm 0.4$ & $291 \pm 3$ & 96 \\
\hline Spark-Plasma polycrystal sintered at $1900{ }^{\circ} \mathrm{C}$ (bulk) & $31.1 \pm 2.9$ & $339 \pm 13$ & 81 \\
\hline
\end{tabular}

Evidence about the high elasticity of the films was revealed by cross-sectional transmission electron microscopy (XTEM) imaging of indents. XTEM was prepared with the lift-out technique using a dual-beam focused ion beam scanning electron microscope (FIB-SEM 1540-ESB, Zeiss, Germany) with a Ga ion source. A Pt layer with $1 \mu \mathrm{m}$ thickness was deposited prior to the milling to protect the indentation area. A FEI Tecnai G2-TF20-UT high resolution transmission electron microscope (HRTEM) with a field emission gun operated at $200 \mathrm{kV}$ was used to observe the cross-sections images and corresponding selected area electron diffraction (SAED) patterns. A brightfield XTEM image of a 0001 textured $\mathrm{ZrB}_{2}$ thin film deposited on $\mathrm{Si}(100)$ after being indented at room temperature with a load of $1.5 \mathrm{mN}$ is displayed in figure $2 \mathrm{~d}$. No delamination was observed in the film/substrate interface, suggesting good interfacial bonding. The XTEM micrograph shows no indication of deformation or defects in the 
nanoindentation zone: it seems that the films just elastically bounced back. Comparison of SAED patterns taken on the Berkovich indentation-deformed zone, as well at the left and right non-indented zones (figures 2a-c), indicate no crystalline degradation in the microstructure of the indented area. Furthermore, the micrograph reveals the presence of a pyramidal-shape transformed area on the silicon substrate than can be attributed to the nanoindentation. Dislocation activity phenomena and other defects can be observed in HRTEM (figure 2e), and the material around the indent seems to be highly stressed probably as a result of a phase transformation, leading to notable bend contour contrast, similar to previous studies for Berkovich nanoindentations on uncoated silicon [15]. Thus, the former observation of no phase transformation in the film supports the measured high elastic recovery of $96 \%$, while the latter observation about the substrate damage shows that the film is stable in high stress fields.

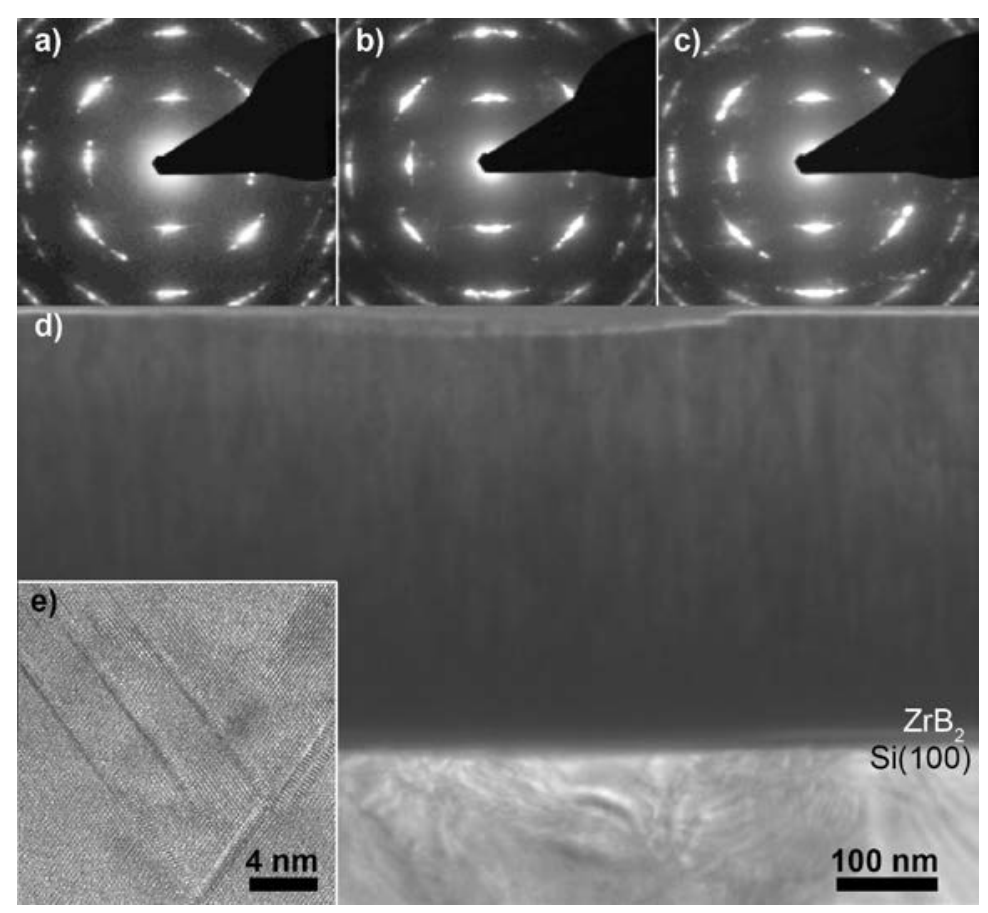

Figure 2: SAED patterns obtained from a) left, b) middle, and c) right parts of indented $\mathrm{Zr} \mathrm{B}_{2}$ film imaged in d) and e) by XTEM and HRTEM (Si substrate only), respectively.

Figure 3 shows the hardness and reduced elastic modulus of the films deposited at $850{ }^{\circ} \mathrm{C}$ and $900{ }^{\circ} \mathrm{C}$ as a function of temperature. The epitaxial films deposited on $4 \mathrm{H}-$ $\mathrm{SiC}(0001)$ present, in the temperature range $25-350{ }^{\circ} \mathrm{C}$, a hardness decrease from 
$47.3 \pm 0.2 \mathrm{GPa}$ to $34.9 \pm 5.0 \mathrm{GPa}$, while $\mathrm{E}_{\mathrm{r}}$ does not change significantly. For the temperature measurement range $400-600{ }^{\circ} \mathrm{C}$, both $\mathrm{H}$ and $\mathrm{Er}_{\mathrm{r}}$ show a change of behavior: $\mathrm{H}$ increases up to $45.4 \pm 9.5 \mathrm{GPa}$ at $450^{\circ} \mathrm{C}$ and then decreases to $32.8 \pm$ 7.0 GPa at $600^{\circ} \mathrm{C}$. On the other hand, $\mathrm{Er}_{\mathrm{r}}$ show erratic changes in the range 338-389 $\mathrm{GPa}$, to finish with a value of $369 \pm 36 \mathrm{GPa}$ at $600^{\circ} \mathrm{C}$, similar to the room temperature value. These observed changes starting at $350-400{ }^{\circ} \mathrm{C}$ are in agreement with a report by Xuan et al on single crystal $\mathrm{ZrB}_{2}$ [6]. They correlated a change of hardness behavior at $-400{ }^{\circ} \mathrm{C}$ with an increase from single to multiple slip plane systems. For instance, $\mathrm{NaCl}$ and $\mathrm{MgO}$ have only $\{110\}$ as slip plane system under indentation at room temperature, but multiple slip plane systems $(\{110\},\{001\}$, and $\{111\})$ at higher temperatures [6]. Nakano et al has also reported that high temperature hardness indentation of single-crystal $\mathrm{ZrB}_{2}$ depends on the indentation plane and the indentation direction, which activate different slip systems [5]. For the weakly $10 \overline{10}$ textured film (figure $3 b$ ), we measured a hardness decrease from $30.8 \pm 0.2 \mathrm{GPa}$ to $24.2 \pm 7.1 \mathrm{GPa}$ at $600{ }^{\circ} \mathrm{C}$, while $\mathrm{Er}$ slightly increases from $243 \pm 8$ to $255 \pm 11 \mathrm{GPa}$. The increase of hardness and elastic modulus at temperatures above $500{ }^{\circ} \mathrm{C}$ for both samples (figures $3 a$ and $3 b$ ) could be related to oxidation of the films or substrates. Rebelo et al [16] pointed out that during high-temperature nanoindentation of $\mathrm{Al}_{2} \mathrm{O}_{3}$ coatings in an $\mathrm{Ar}+\mathrm{N}_{2}+\mathrm{H}$ atmosphere (similar to our experiments), oxidation of their cemented carbide substrate might result in falsification of the load/unloading curves. IN our films, we have also seen indications for oxidation, e.g., interference colors at the sample surface after measuring up to $600{ }^{\circ} \mathrm{C}$, which could also result in an apparent increase of $\mathrm{H}$ and $\mathrm{E}_{\mathrm{r}}$.
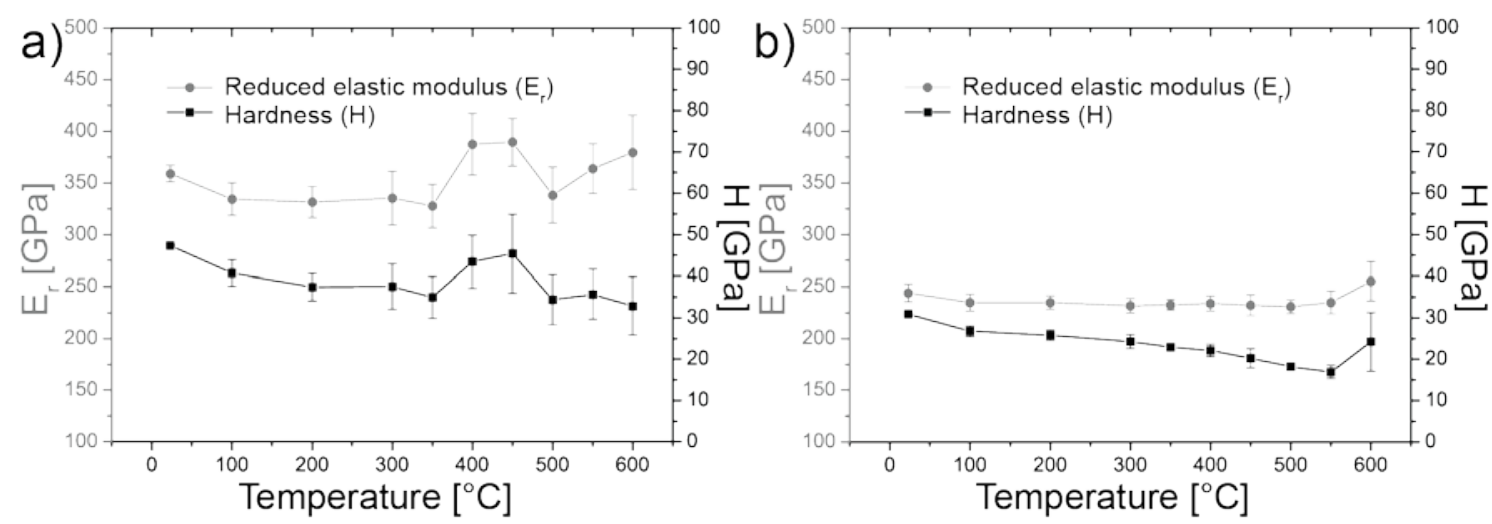

Figure 3: Hardness and reduced elastic modulus of $\mathrm{ZrB}_{2}$ films (a) epitaxial film grown on $4 \mathrm{H}$-SiC (0001) at $900{ }^{\circ} \mathrm{C}$; (b) weakly textured film deposited on Si(100) at $850{ }^{\circ} \mathrm{C}$, as a 
function of temperature measurement. Error bars represent the mean value and statistical dispersion of 20-30 measurements per temperature.

The high temperature mechanical properties of our films are related to their crystal quality. To obtain films with the highest hardness and elastic modulus, the $\mathrm{ZrB}_{2}$ films need to be epitaxially grown on $\mathrm{SiC}(0001)$ at $900^{\circ} \mathrm{C}$. Degraded mechanical properties are obtained, instead, when the $\mathrm{ZrB}_{2}$ films have a weak texture. A low quality $\mathrm{ZrB}_{2}$ microstructure is obtained as the result of a film/substrate reaction during growth on $\mathrm{Si}(100)$ at $850{ }^{\circ} \mathrm{C}$. XTEM and HRTEM analysis of the film-substrate interface in this film reveals a fibrous $\mathrm{ZrB}_{2}$ microstructure, a rough substrate surface, and the presence of an amorphous material on the interface (Figure 4).

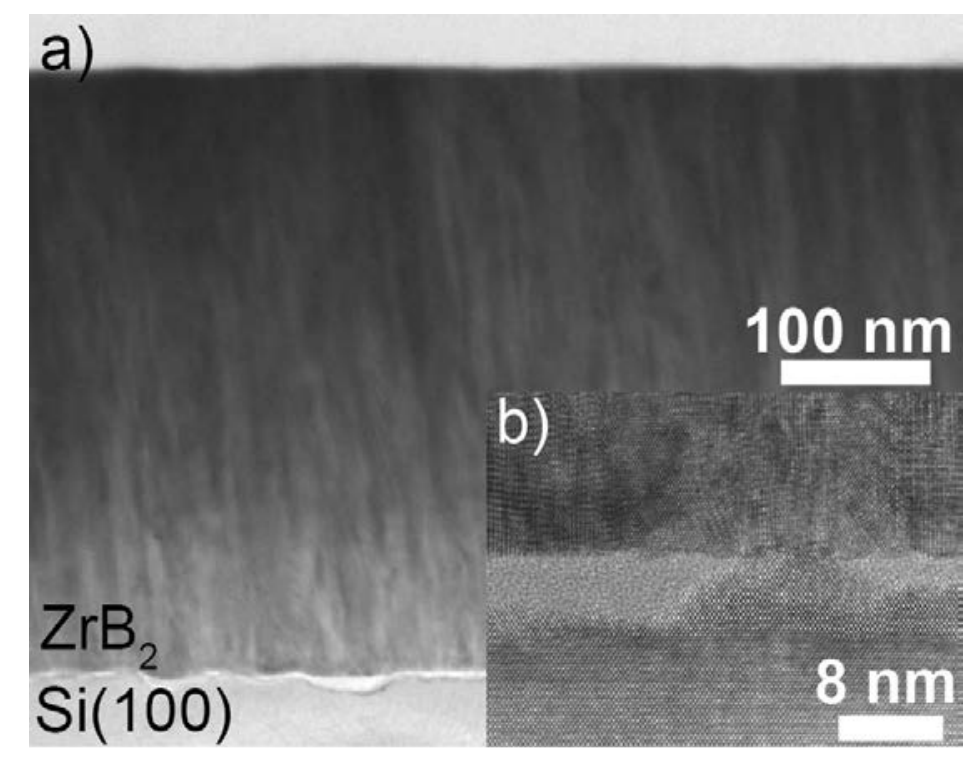

Figure 4: XTEM micrograph of $\mathrm{ZrB}_{2}$ film grown on $\mathrm{Si}(100)$ at $850{ }^{\circ} \mathrm{C}$. The inset shows a HRTEM image of the Si/film interface

The few available high temperature hardness studies of bulk $\mathrm{ZrB}_{2}$ that we discussed have employed Knoop [6] or Vickers [7-9] hardness measurements, making comparisons with our nanoindentation data on thin films difficult. Table 2 compares the $\mathrm{H}$ values at room temperature and $600{ }^{\circ} \mathrm{C}$ for our films and those from the 
aforementioned published reports, as well as the relative variation of hardness in that temperature range. We can see that our films grown on $4 \mathrm{H}-\mathrm{SiC}(0001)$ have the highest values at both temperatures, which can be correlated to the high crystal quality of our films, as we already observed in our epitaxial $\mathrm{ZrB}_{2}$ films grown on $\mathrm{Al}_{2} \mathrm{O}_{3}(0001)$ [12]. Regarding the film grown on $\mathrm{Si}(100)$ at $850{ }^{\circ} \mathrm{C}$, the hardness values at both temperatures are slightly higher than the bulk single-crystal material reported by Nakano et al [5], and have lower hardness variation. Furthermore, the relative elastic modulus decrease $\Delta \mathrm{E} / \mathrm{E}$ in the temperature range of $25-600{ }^{\circ} \mathrm{C}$, which can be correlated to atomic bonding deterioration, was reported to be $\sim 3 \%[9,10]$, which is similar to the $E_{r}$ reduction in our epitaxial and weakly textured samples grown on $\mathrm{SiC}(0001)$ and $\mathrm{Si}(100)$, respectively.

Table 2: Hardness temperature variation for different samples

\begin{tabular}{|l|c|c|c|}
\hline \multirow{2}{*}{ ZrB $_{2}$} & \multicolumn{2}{|c|}{$\mathbf{H} \mathbf{( G P a )}$} & \multirow{2}{*}{$\mathbf{\Delta H} / \mathbf{H}(\%)$} \\
\cline { 2 - 3 } & $\mathbf{2 5}^{\circ} \mathbf{C}$ & $\mathbf{6 0 0}{ }^{\circ} \mathbf{C}$ & \\
\hline Epitaxial film/4H-SiC(0001) & $47.3 \pm 0.2$ & $32.8 \pm 7.0$ & 30.6 \\
\hline Weakly textured film/Si(100) & $30.8 \pm 0.2$ & $24.2 \pm 7.1$ & 21.4 \\
\hline Bulk single-crystal $\{0001\}[5](*)$ & 27.0 & 15.0 & 44.4 \\
\hline Bulk single-crystal $\{10 \overline{10}\}[5]\left(^{*}\right)$ & 20.0 & 10.0 & 50.0 \\
\hline Bulk single-crystal [6] $\left(^{*}\right)$ & 21.3 & 10.0 & 53.1 \\
\hline Bulk polycrystalline [7] $\left(^{*}\right)$ & 30.0 & 8.5 & 71.7 \\
\hline
\end{tabular}

(*) Published data does not provide error bars.

In summary, the hardness and relative elastic modulus of stoichiometric epitaxial $\mathrm{ZrB}_{2}$ films were measured for the first time by a nanoindentation technique with in situ heating in the range $25-600{ }^{\circ} \mathrm{C}$. The epitaxial film deposited on $4 \mathrm{H}-\mathrm{SiC}(0001)$ have $\mathrm{H}=47.3 \pm 0.2 \mathrm{GPa}$ and $\mathrm{E}_{\mathrm{r}} 359 \pm 8 \mathrm{GPa}$ at room temperature, and $\mathrm{H}=32.8 \pm 7.0 \mathrm{GPa}$ and $E_{r}=369 \pm 36 \mathrm{GPa}$ at $600{ }^{\circ} \mathrm{C}$. The $10 \overline{10}$ textured film on $\mathrm{Si}(100)$ have $\mathrm{H}=30.8 \pm$ $0.2 \mathrm{GPa}$ and $\mathrm{E}_{\mathrm{r}}=243 \pm 8 \mathrm{GPa}$ at room temperature, which change to $\mathrm{H}=24.2 \pm 7.1$ $\mathrm{GPa}$ and $\mathrm{Er}=255 \pm 11 \mathrm{GPa}$ at $600{ }^{\circ} \mathrm{C}$. Nanoindentation, TEM, and SAED analyses reveals high elastic recovery of $96 \%$ for both films, with no phase transformations taking place during or after the indentations. Due to the superior hardness and elastic modulus at high temperature, $\mathrm{ZrB}_{2}$ films are a promising material for applications which require hard films at high temperature, such as metal cutting. 
$\mathrm{EB}, \mathrm{LH}$, and $\mathrm{HH}$ acknowledge financial support from the Swedish Government Strategic Research Area in Materials Science on Functional Materials at Linköping University (Faculty Grant SFO-Mat-LiU No.2009-00971). LT acknowledges support from Swedish Research Council (VR), contract 621-2010-3921. The Knut and Alice Wallenberg Foundation supported our thin film and electron microscopy laboratories.

The authors acknowledge Dr. Shu-Qi Guo, National Institute for Materials Science, Tsukuba (Japan) for providing a bulk $\mathrm{ZrB}_{2}$ sample for nanoindentation comparison.

\section{REFERENCES}

[1] D. Munz and F. Fett, Ceramics: Mechanical Properties, Failure Behaviour, Materials Selection,: Springer, New York, 2013.

[2] S.-Q. Guo, J. Eur. Ceram. Soc. 29 (2009) 995.

[3] L. Tengdelius, J. Birch, J. Lu, L. Hultman, U. Forsberg, J. Janzén and H. Högberg, Phys. Status Solidi A, 211 (2014) 636.

[4] L. Tengdelius, G. Greczynski, M. Chubarov, J. Lu, U. Forsberg, L. Hultman, E. Janzén, and H. Högberg, J. Cryst. Growth 430 (2015) 55.

[5] K. Nakano and H. Matsubara, J. Less-Common Met. 47 (1976) 259.

[6] Y. Xuan, C.-H. Chen and O. Shigeki, J. Phys. D Appl. Phys. 35 (2002) L.98.

[7] L. Bsenko and T. Lundström, J. Less-Common Met. 34 (1974) 273.

[8] J. Wang, E. Feilden-Irving, L. J. Vandeperre and F. Giuliani, Ceram. Eng. Sci. Proc. 33 (2012) 187.

[9] N. Okamoto, M. Kusakari, K. Tanaka, H. Inui and S. Otani, Acta Mater. 58 (2011) 76.

[10] D. E. Wiley, W. R. Manning and J. R. Hunter, J. Less-Common Met. 18 (1969) 149. 
[11] L. Tengdelius, M. Samuelsson, J. Jensen, J. Lu, L. Hultman, U. Forsberg, E. Janzén and H. Högberg, Thin Solid Films 550 (2014) 285.

[12] L. Tengdelius, E. Broitman, J. Lu, F. Eriksson, J. Birch, T. Nyberg, L. Hultman and H. Högberg, Acta Mater. 111 (2016) 166.

[13] W. Oliver and G. Pharr, J Mater. Res. 7 (1992) 1564.

[14] S. Guo, N. Toshiyuki, K. Yutaka and J. Yang, J. Am. Ceram. Soc. 91 (2008) 2848.

[15] I. Zarudi, L. C. Zhang, W. C. D. Cheong and T. X. Yu, Acta Mater. 53 (2005) 4795.

[16] M. Rebelo de Figueiredo, M. D. Abad, A. J. Harris, C. Czettl, C. Mitterer, P. Hosemann, Thin Solid Films 578 (2015) 20. 